\title{
Quantum Dot Assembly Driven by Electrochemically Generated Metal-ion Crosslinkers
}

\author{
Chathuranga C. Hewa-Rahinduwage, ${ }^{[a]}$ Karunamuni L. Silva, ${ }^{[a]}$ Stephanie L. Brock, ${ }^{*[a]}$ Long \\ Luo*[a] \\ [a] Department of Chemistry, Wayne State University, Detroit, MI 48220, U. S. A.
}

Chemicals and Materials. Trioctylphosphine oxide [TOPO, 99\%] bis(trimethylsilyl)sulfide (TMS), 1-tetradecylphosphonic acid (TDPA), selenium powder [Se, 99.99\%], thioglycolic acid (TGA), 11mercaptoundecanoic acid (MUA) and tetramethylammonium hydroxide (TMAH) were purchased from Sigma-Aldrich; trioctylphosphine [TOP > 85\%], and cadmium oxide [CdO, 99.99\%] were purchased from Strem chemicals.

Synthesis of CdS QDs. A mixture of TOPO (3.0 g, $7.8 \mathrm{mmol}), \mathrm{CdO}(0.06 \mathrm{~g}, 0.47 \mathrm{mmol})$, and TDPA $(0.23 \mathrm{~g}, 0.83 \mathrm{mmol})$ were added into $100 \mathrm{~mL}$ Schlenk flask. After connecting the flask to the active vacuum, it was heated to $150^{\circ} \mathrm{C}$ and maintained for 20 minutes under stirring to liquify. The vacuum was disconnected after 20 minutes, and gradually a slow, continuous $\mathrm{Ar}$ flow was established through the system. The temperature was increased to $350{ }^{\circ} \mathrm{C}$ and maintained until the flask's content became colorless (60 - 90 minutes). The temperature was then reduced to $320^{\circ} \mathrm{C}$ and a $2 \mathrm{~mL}$ aliquot of TOP (stored and measured in the glovebox) was injected. Next, the temperature was raised to $370{ }^{\circ} \mathrm{C}$, and when the temperature was reached, a mixture of $2.4 \mathrm{~mL}$ TOP and $90 \mu \mathrm{L}$ TMS was injected. After maintaining the reaction mixture at $370^{\circ} \mathrm{C}$ for 15 minutes, the temperature was reduced to $75^{\circ} \mathrm{C}$, and the Ar purge was stopped. After 18 hours under static $\mathrm{Ar}$, the flask was removed from the Schlenk line connection, and the content in the flask was transferred into a $50 \mathrm{~mL}$ centrifuge vial using $15 \mathrm{~mL}$ of toluene. The vial was closed and sonicated for 10 minutes. Then, the product mixture was centrifuged at $3000 \mathrm{rpm}$ for 14 minutes. Insoluble reactants and products were precipitated at this stage, and the supernatant was transferred to another centrifuge vial into which methanol was added until the solution became cloudy/turbid. The vial was centrifuged, and QDs were precipitated at this stage while soluble unreacted reactants were left in the supernatant. The supernatant was discarded, and the precipitated QDs were redispersed in toluene. After another 14 minutes of centrifugation to remove any insoluble matter, the same purification steps were repeated one more time (sonication, precipitation using methanol, centrifugation, and redispersion in toluene). All the steps were carried out while minimizing exposure of the QDs to light. The purified QD solution was stored in the dark until the ligand exchange.

Synthesis of CdSe QDs. In a Schlenk flask, $0.0254 \mathrm{~g} \mathrm{(0.2} \mathrm{mmol)} \mathrm{CdO,} 0.08 \mathrm{~g}$ TDPA, $4.0 \mathrm{~g}$ TOPO were combined. Under stirring, and the mixture was degassed for 20 min under active vacuum at $150^{\circ} \mathrm{C}$. The vacuum was disconnected after 20 minutes, and gradually, a slow, continuous Ar flow was established (a needle was introduced to the bubbler at the top septum). The temperature was then increased to $330^{\circ} \mathrm{C}$ and maintained until the solution became colorless (60-90 minutes). Then the temperature was reduced back to $150^{\circ} \mathrm{C}$ and a mixture of $0.02 \mathrm{~g}(0.25 \mathrm{mmol})$ Se and $2.4 \mathrm{~mL}$ TOP solution was injected (Se and TOP mixture was sonicated for an hour before injecting). Next, the temperature was increased to $250^{\circ} \mathrm{C}$ and maintained over 4 hours. After 4 hour annealing time, the solution temperature was reduced to $75^{\circ} \mathrm{C}$ and the CdSe QD solution was transferred into a $50 \mathrm{~mL}$ centrifuge vial and purified as described above (precipitation using methanol and redispersion in toluene). All the steps were carried out while minimizing exposure of the QDs to light. The purified QD solution was stored in the dark until the ligand exchange. 
Ligand exchange with TGA and MUA. First, a TGA solution was prepared by adding TGA (138 $\mu \mathrm{L}$, equivalent of $4 \times$ moles $\mathrm{CdO}$ used in the CdS synthesis) into $10 \mathrm{~mL}$ of methanol. Then, the $\mathrm{pH}$ was adjusted to 10 using TMAH. The purified QD dispersion was mixed with the TGA solution and sonicated for $1 \mathrm{~h}$ in the dark. The solution was removed, and ethyl acetate was added until cloudy. The mixture was centrifuged for 10 minutes, and the supernatant containing unreacted TGA was discarded. QDs were redispersed in methanol, and purification was repeated by precipitation and redispersion with ethyl acetate and methanol, respectively.

Ligand exchange with MUA followed a similar procedure as described above, only using an MUA solution prepared by dissolving $431 \mathrm{mg}$ of MUA powder in $10 \mathrm{~mL}$ methanol.

Solvent exchange of wet gels for aerogel formation. Each day the stored gel was taken out, and the solvent was exchanged with a fresh aliquot of acetone twice. The purpose was to remove all the remaining methanol before the gelation. The aerogel was prepared inside a $10 \mathrm{~mL}$ glass vial capped with a plastic cap with pin-holes to let the liquid $\mathrm{CO}_{2}$ flow in and the acetone flow out. The required amount of the stored wet gels was transferred into this vial and filled to the top with acetone.
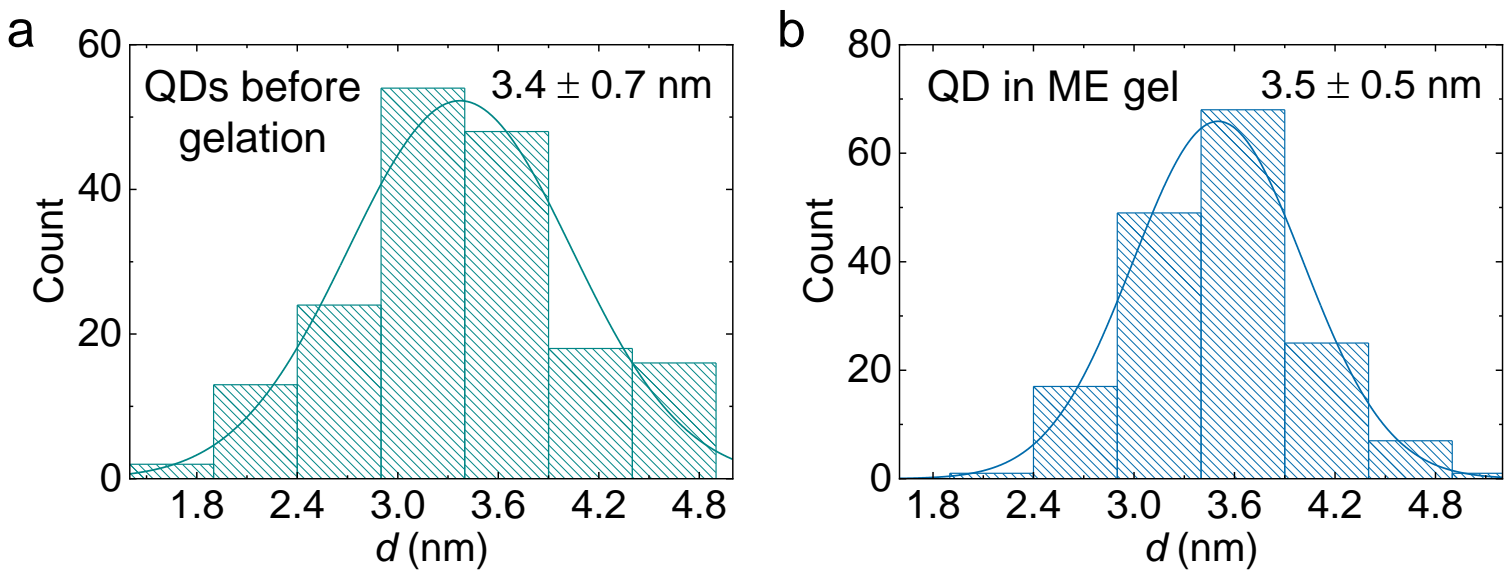

Figure S1. a, Size distribution of the QDs before ME-gelation. b, Size distribution of the QD building blocks in the ME-gel. The sizes were obtained by analyzing the TEM images of QDs and the QD ME-gel using ImageJ software. 


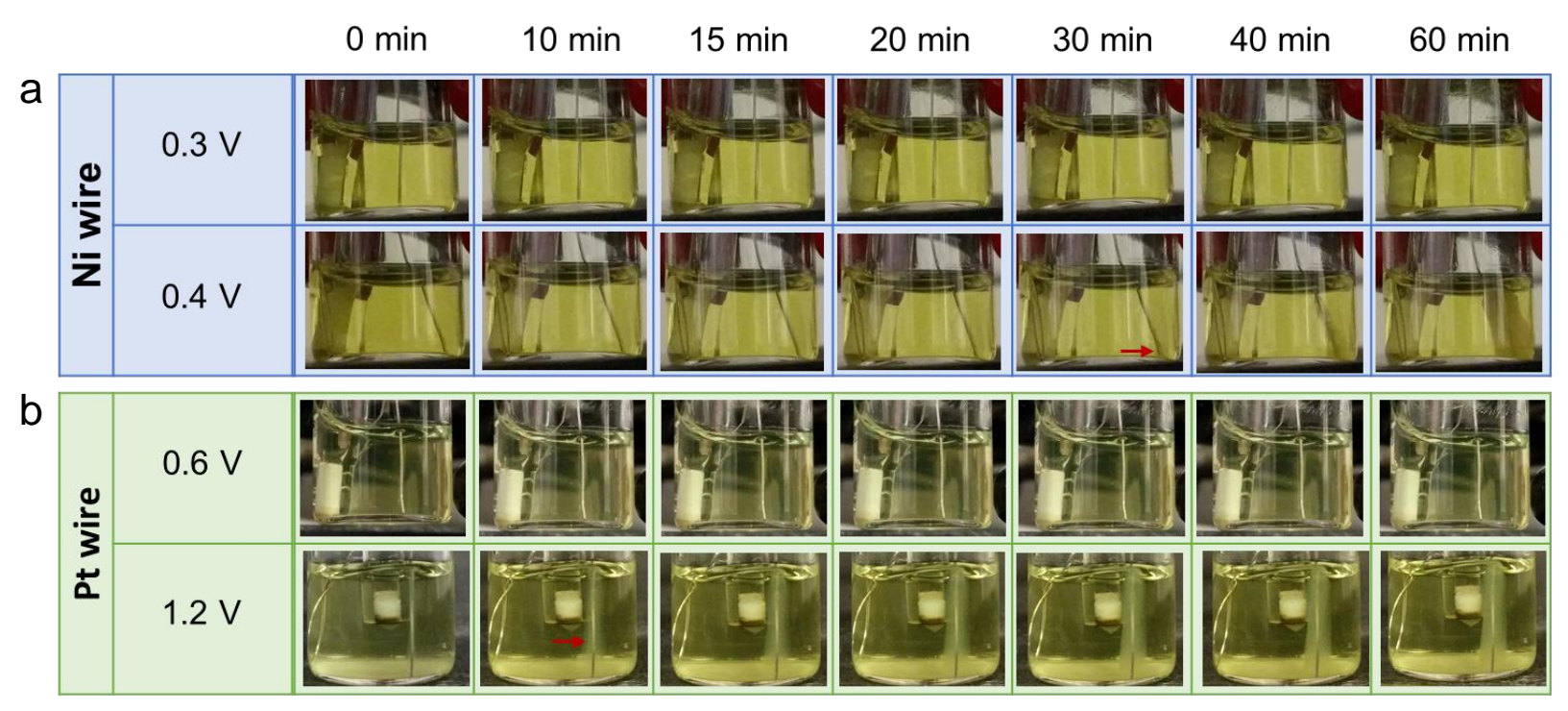

Figure S2. TGA-capped CdS QD electrogelation. a, ME-gelation using a Ni wire anode as a function of oxidation time at 0.3 and $0.4 \mathrm{~V}$ vs $\mathrm{Ag} / \mathrm{AgCl} / \mathrm{sat}$. $\mathrm{KCl}$. No ME-gelation was observed at $0.3 \mathrm{~V}$ after one hour. ME-gel formation was observed at electrode potentials $0.4 \mathrm{~V}$ within 1 hour when a Ni wire was used as the working electrode. b, OE-gelation using a Pt wire anode as a function of time at 0.6 and $1.2 \mathrm{~V}$. No gels were observed after an hour at $0.6 \mathrm{~V}$. To obtain a similarly-sized gel as in (a) at $0.4 \mathrm{~V}$, the potential requirement is $1.2 \mathrm{~V}$.

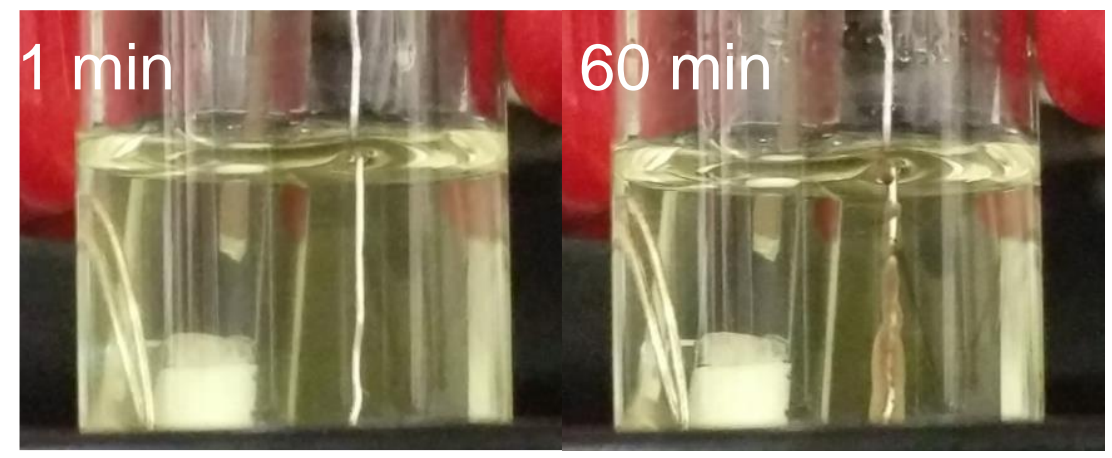

Figure S3. ME-gelation of MUA-capped CdS QDs at a Ni wire electrode at $0.5 \mathrm{~V}$ vs $\mathrm{Ag} / \mathrm{AgCl} / \mathrm{sat}$. $\mathrm{KCl}$. 

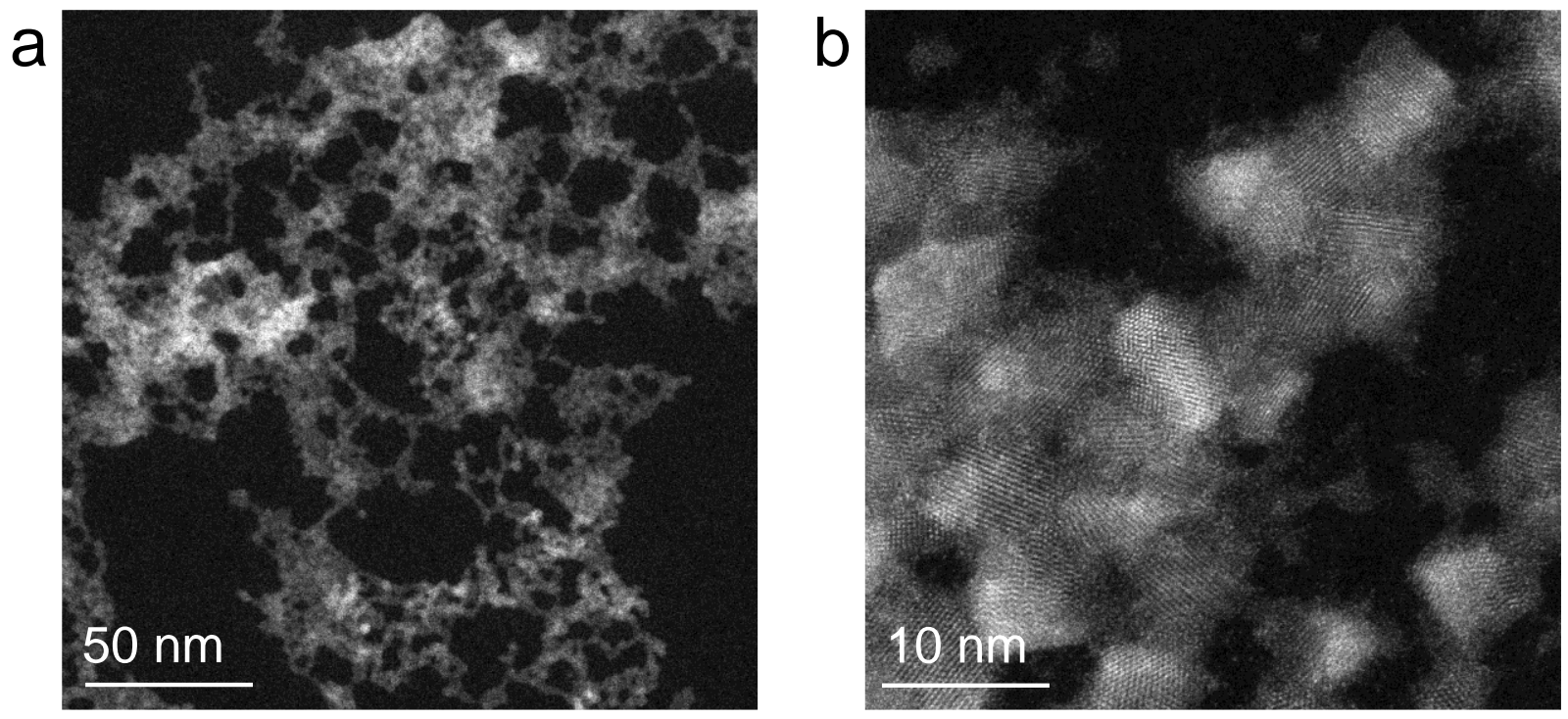

Figure S4. Typical STEM micrographs of OE-gels prepared from TGA-capped CdS QDs at 2.0 V using a Pt wire electrode. a, A low-magnification STEM image that shows the 3D mesoporous gel structure. $b$, A high-magnification STEM image of the same gel shows the QD building blocks are directly connected without any notable gaps between them. 

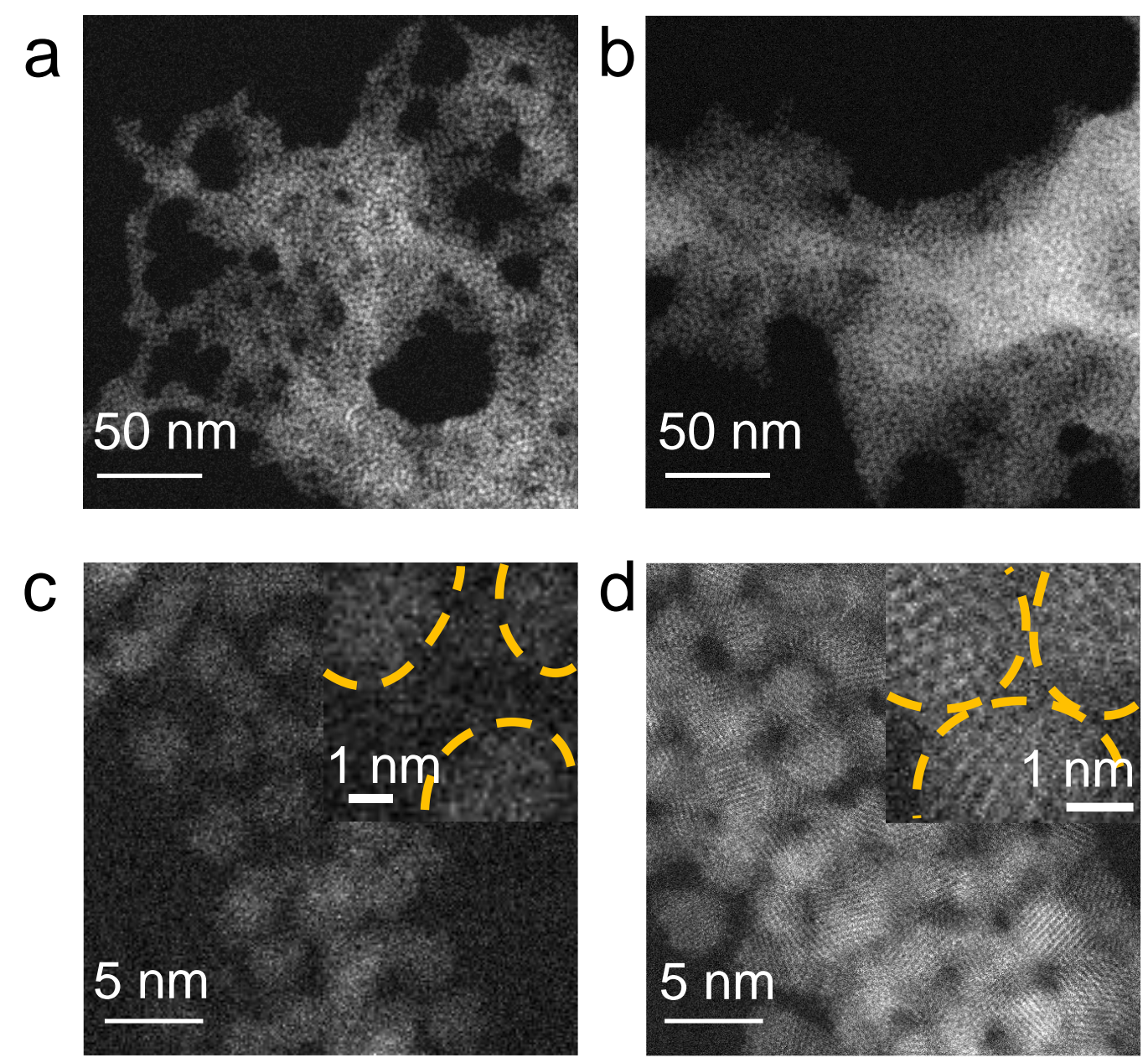

Figure S5. $a-b$, Low-magnification and $c-d$, high-magnification STEM micrographs of ME-gels prepared using a Ni wire electrode at $1 \mathrm{~V}(\mathrm{a}, \mathrm{c})$ and OE-gels prepared using a Pt wire electrode at $2 \mathrm{~V}(\mathrm{~b}, \mathrm{~d})$ from MUA-capped CdS QDs. Insets in c and d show significant gaps between the QDs in the ME-gel relative to its OE-gel counterpart, respectively. 

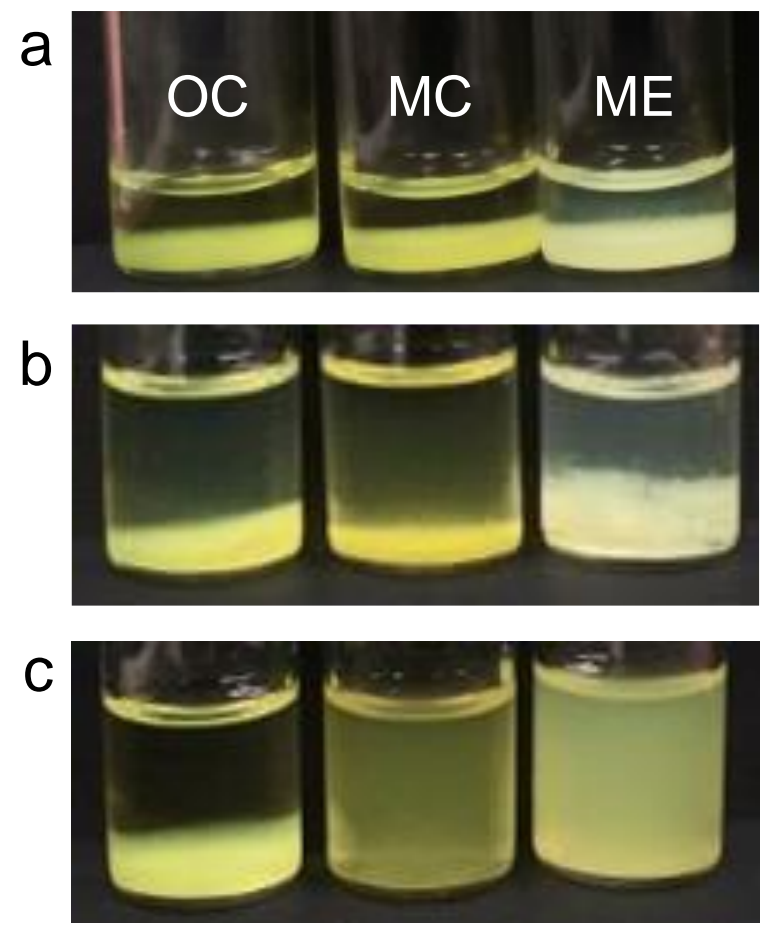

Figure S6. EDTA dispersion tests for CdS QD gels prepared by three different methods: the OCgel was prepared by adding a chemical oxidant to form disulfide crosslinks between QDs, the MCgel was prepared by adding $\mathrm{Ni}^{2+}$ ions to TGA-capped QDs, and the ME-gel was prepared by electrochemically releasing $\mathrm{Ni}^{2+}$ into a solution of TGA-capped QDs. a, As-prepared. b. After the addition of water (control). c, After the addition of EDTA solution. 


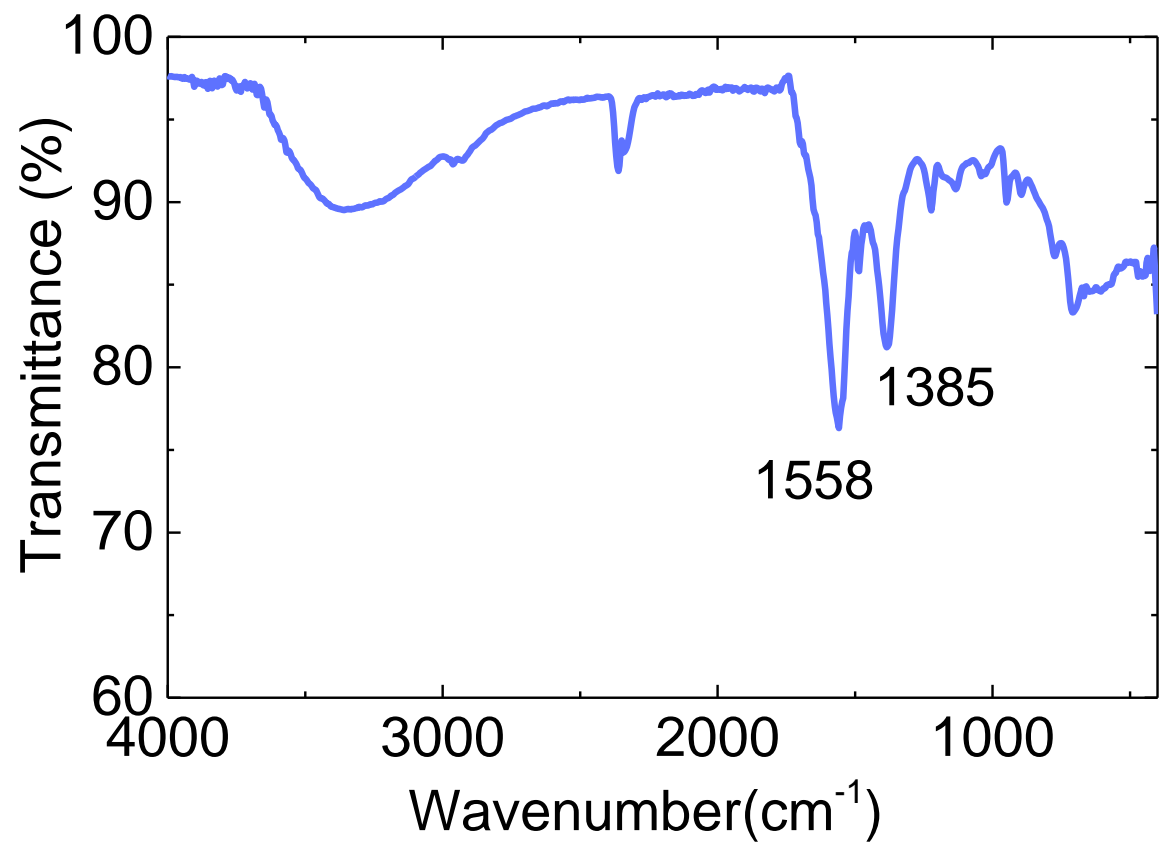

Figure S7. Infrared spectrum of a CdS ME-gel. The peaks at 1558 and $1385 \mathrm{~cm}^{-1}$ correspond to the asymmetric and symmetric stretching vibrations of the carboxylate groups in the ME-gel, respectively. The difference between the two wavenumbers, $\Delta v$, is a parameter that identifies the type of bonding between the metal and carboxylate moiety: a value above $250 \mathrm{~cm}^{-1}$ signifies the monodentate coordination, a value in the range of $120-250 \mathrm{~cm}^{-1}$ signifies the bridging mode, while a difference below $120 \mathrm{~cm}^{-1}$ corresponds to chelation. $\Delta v=173 \mathrm{~cm}^{-1}$ for the CdS ME-gel.

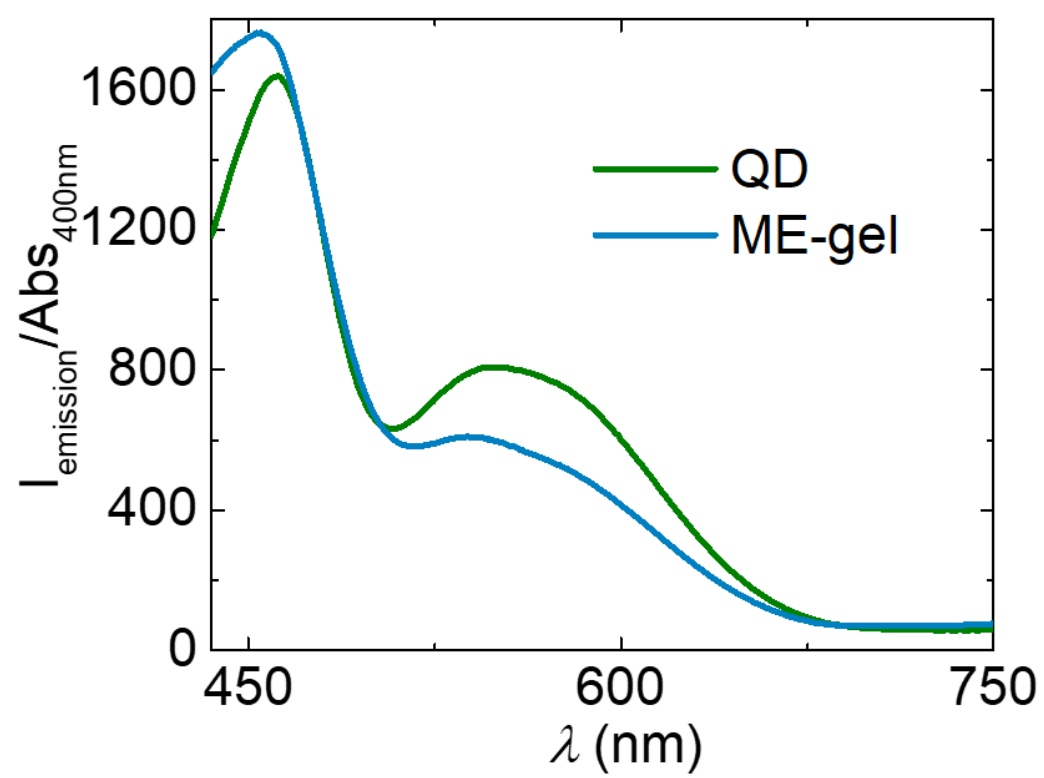

Figure S8. Photoluminescence spectra for CdS QDs and CdS QD ME-gel. The PL intensity was normalized to the absorbance at the excitation wavelength (400 nm). 
a

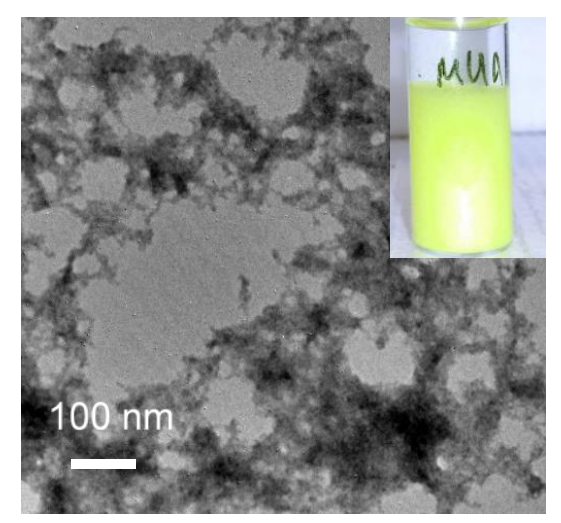

C

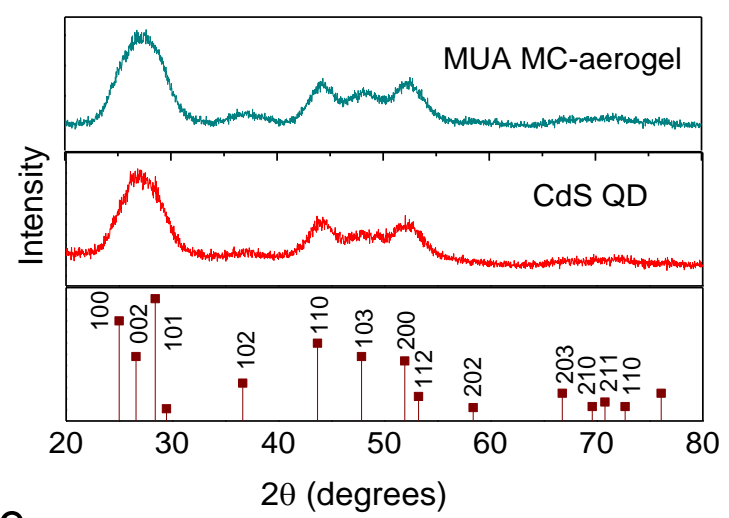

e

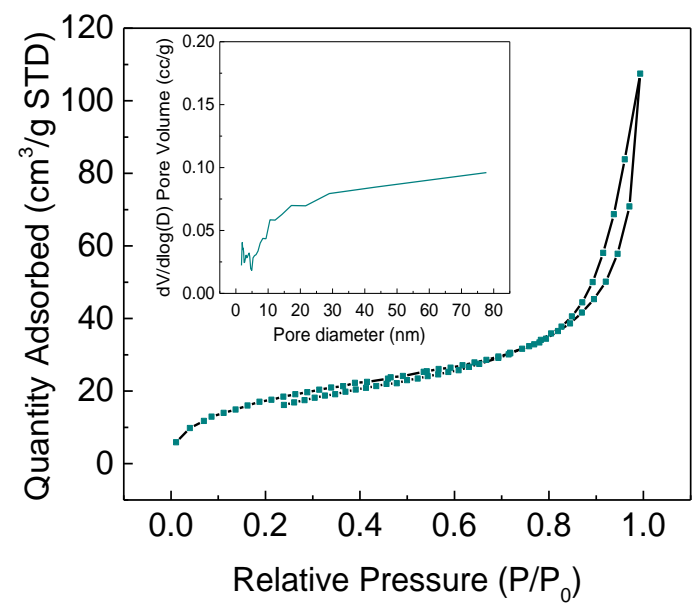

b

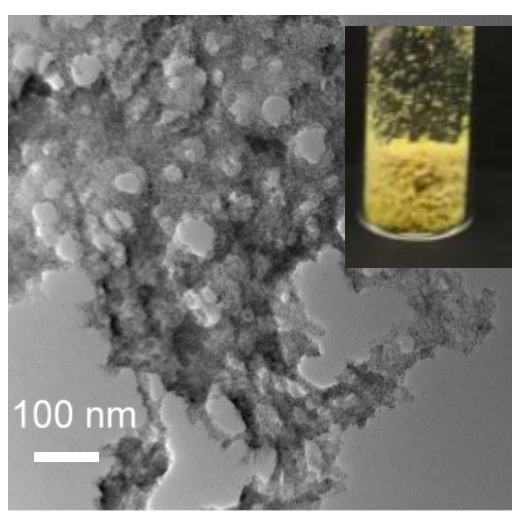

d

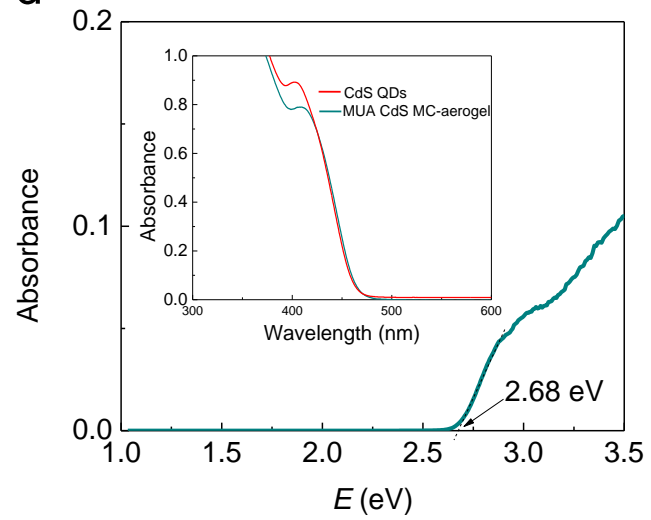

f

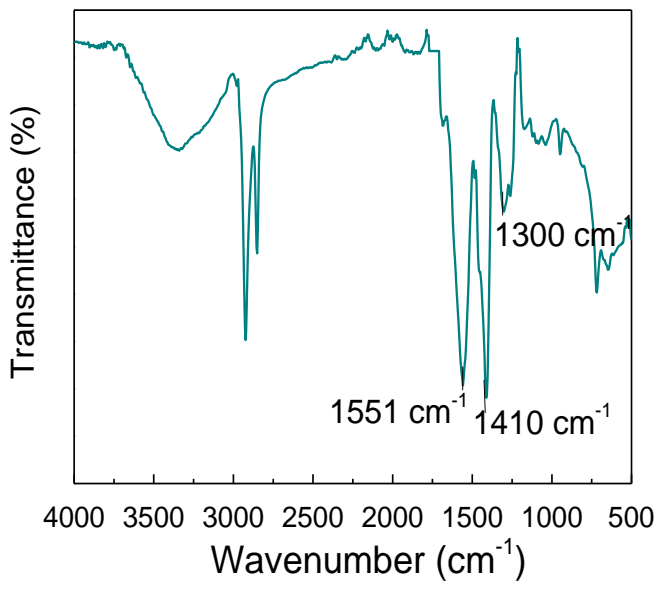

Figure S9: Characterization of the MC-gels produced by introduction of $\mathrm{Ni}^{2+}$ to MUA-capped CdS QDs. a-b, Low magnification TEM images and corresponding photographs (insets) of an MC-wet gel and MC-aerogel, respectively. c, Powder X-ray diffraction (PXRD) patterns of MC-aerogel and QDs; the hexagonal CdS (wurtzite) PXRD pattern is shown as a reference (PDF 00-001-0780). $\mathrm{d}$, Diffuse reflectance spectrum of an MC-aerogel and the UV-Vis absorption spectrum of CdS QDs and an MC-aerogel. e, $\mathrm{N}_{2}$ adsorption-desorption isotherms and the Barrett-Joyner-Halenda pore size distribution plot (inset) for the CdS MC-aerogel. $f$, IR analysis of the CdS MC-aerogel $\left(\Delta v=141 \mathrm{~cm}^{-1}\right)$. 

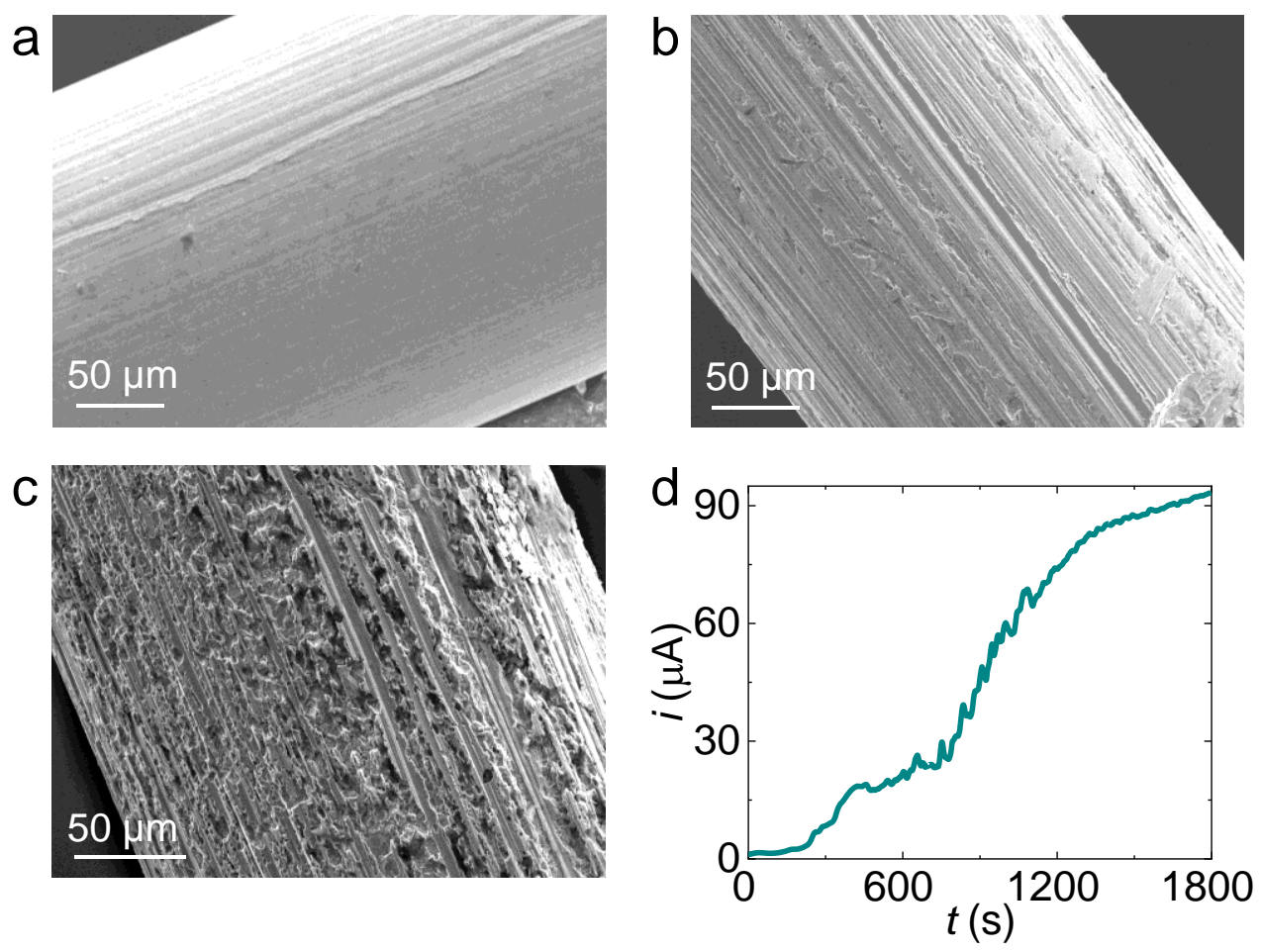

Figure S10. SEM images of the Ni wire anode before and after ME-gelation. a, As-purchased Ni wire surface. $\mathrm{b}, \mathrm{Ni}$ wire after mechanical polishing using sandpaper. $\mathrm{C}, \mathrm{Ni}$ wire after electrodissolution in methanol at $0.4 \mathrm{~V}$ for 30 mins. Many cavities were observed on the wire surface. $d$, The corresponding current-time trace during $\mathrm{Ni}$ electrodissolution, showing a continuous current increase.

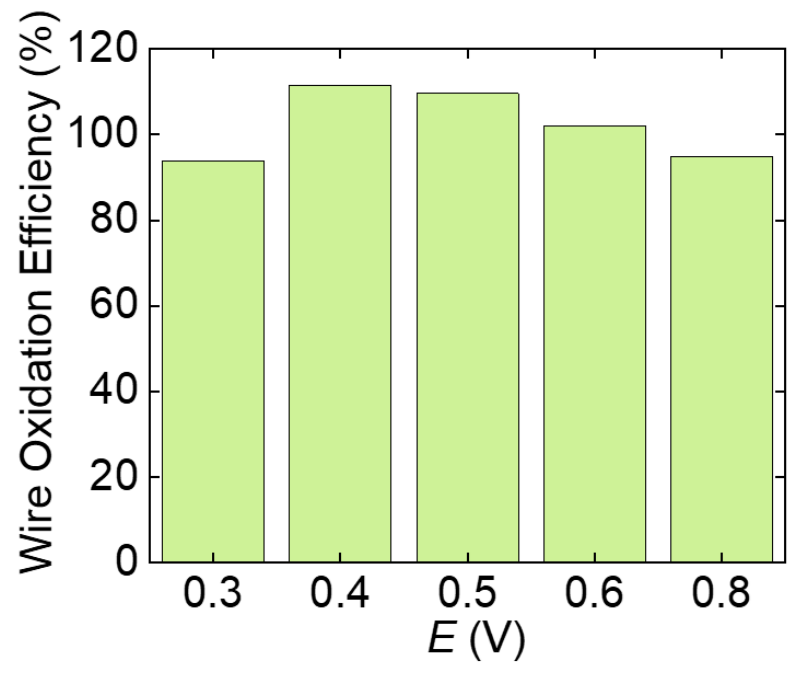

Figure S11. Ni wire oxidation efficiency in methanol under different electrode potentials. The oxidation efficiency is defined as the percentage of the total charge that is used to oxidize $\mathrm{Ni}$ to $\mathrm{Ni}^{2+}$. For all potentials $\leq 0.8 \mathrm{~V}$, the oxidation efficiency was above $90 \%$, indicating the oxidation of $\mathrm{Ni}$ to $\mathrm{Ni}^{2+}$ is the only anodic reaction under these electrode potentials. 
a

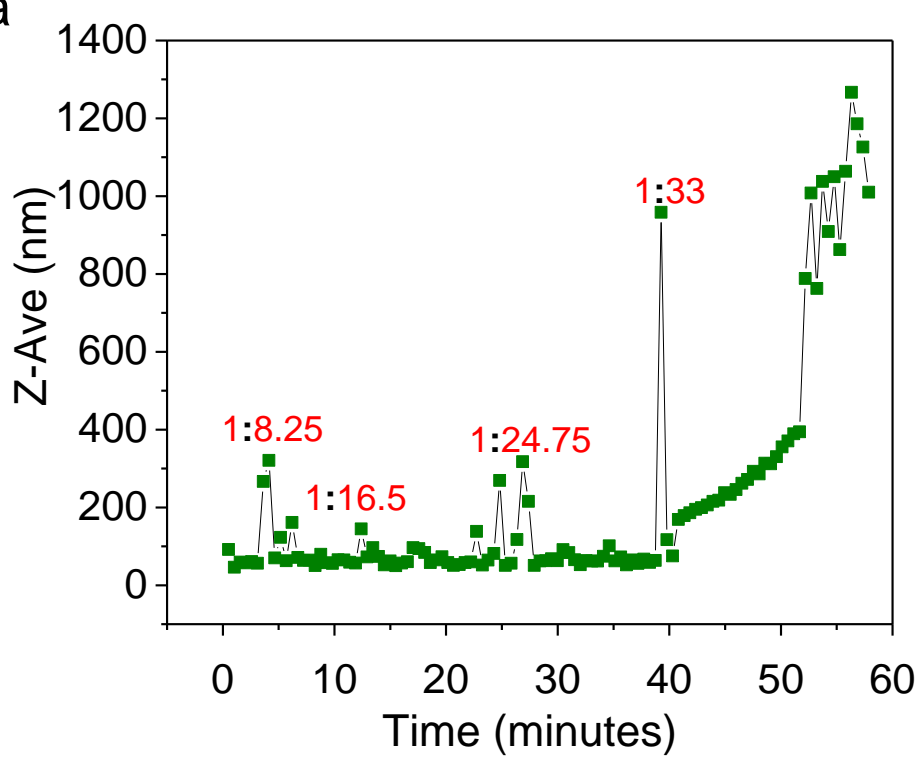

b

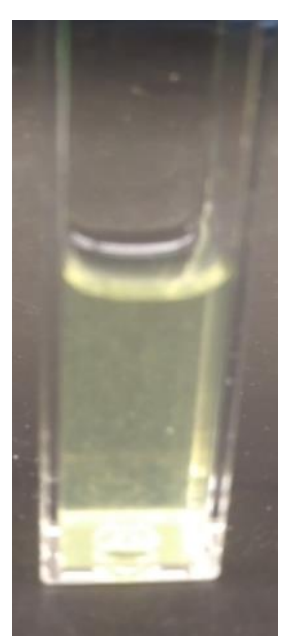

Figure S12: a, Change in the equilibrium hydrodynamic radius $\left(\bar{R}_{h}\right)$ as a function of time during the addition of $\mathrm{Ni}^{2+}$ to $2 \mathrm{~mL}$ of $1.52 \mu \mathrm{M}$ TGA-capped CdS QD sol (4 aliquots, $5.0 \mu \mathrm{L}$ of $5.0 \mathrm{mM}$ $\mathrm{Ni}^{2+}$. Sustained aggregation was initiated between a ratio of $\mathrm{Ni}^{2+}:$ CdS of 26 and 33. The spikes in (a) correspond to the interference from the pipette tip during $\mathrm{Ni}^{2+}$ addition. $\mathrm{b}$, Photograph of the cuvette after the introduction of $\mathrm{CdS}: \mathrm{Ni}^{2+}=1: 33$ showing gel formation.

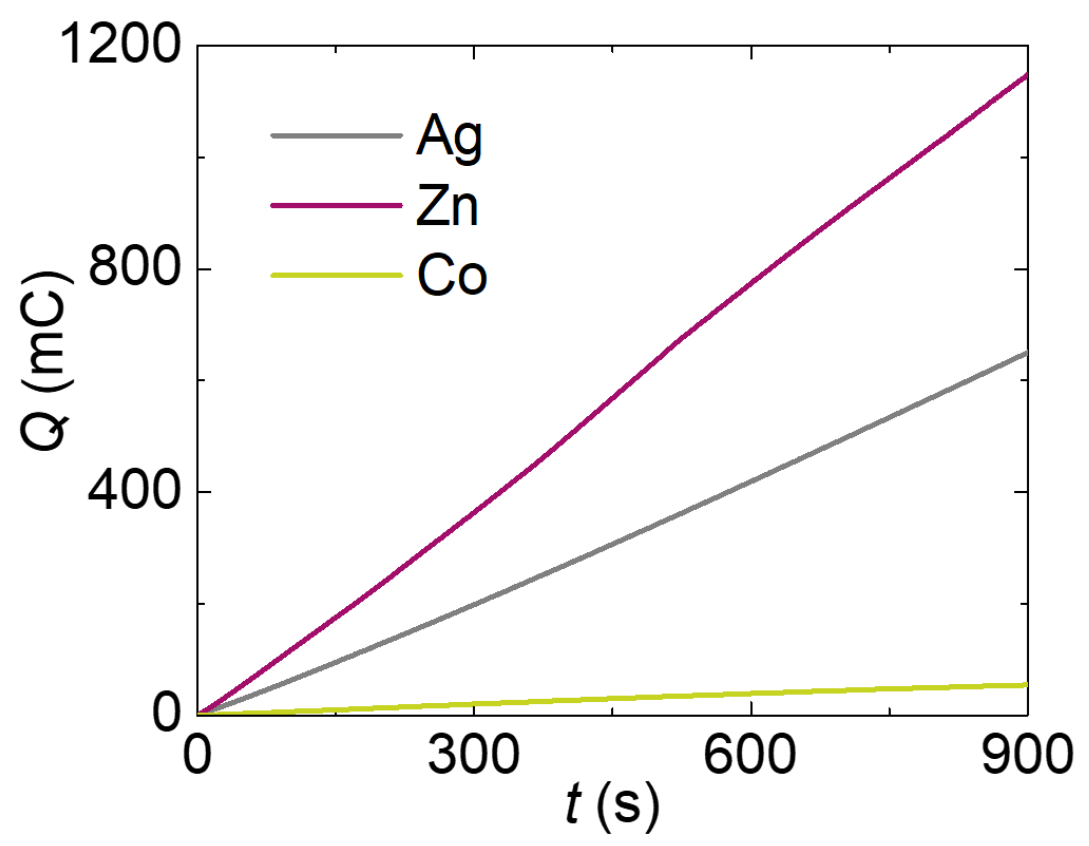

Figure S13. Charge vs. time plots for the ME-gelation of CdS QDs using different metal electrodes at 1.2 V. The photographs of the produced ME-gels are shown in Figure 4a-c. 


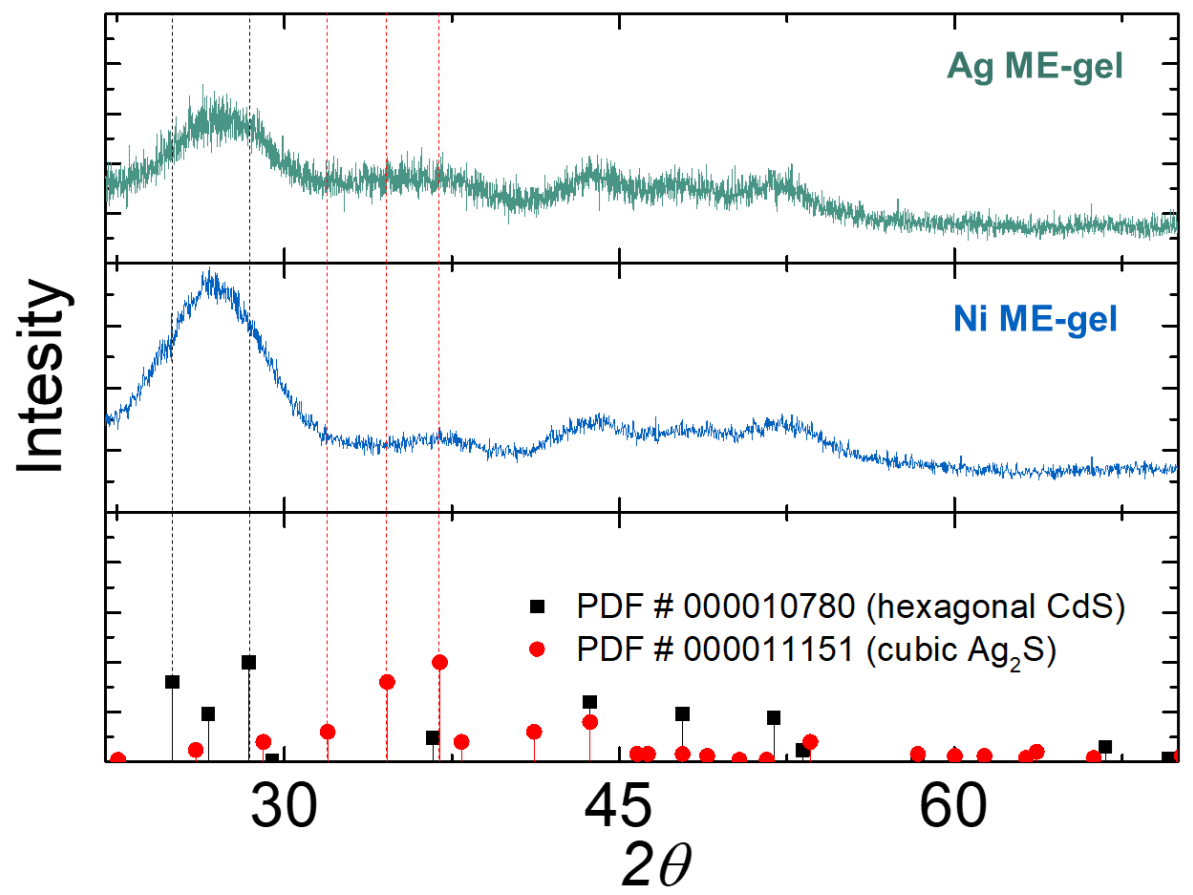

Figure S14. PXRD patterns of ME-gels prepared using $\mathrm{Ag}$ and Ni electrodes. The hexagonal $\mathrm{CdS}$ (PDF 00-001-0780) and cubic $\mathrm{Ag}_{2} \mathrm{~S}$ (PDF 00-001-1151) PXRD patterns are shown as the references in the stick diagram. Small changes in intensity of the highlighted peaks may reflect the presence of $\mathrm{Ag}_{2} \mathrm{~S}$ (the peaks at $25^{\circ}, 27^{\circ}$, and $28^{\circ}$ that correspond to hexagonal CdS decrease whereas the peaks at $32^{\circ}, 35^{\circ}$, and $37^{\circ}$ that correspond to cubic $\mathrm{Ag}_{2} \mathrm{~S}$ increases relative to the $\mathrm{Ni}$ counterpart).
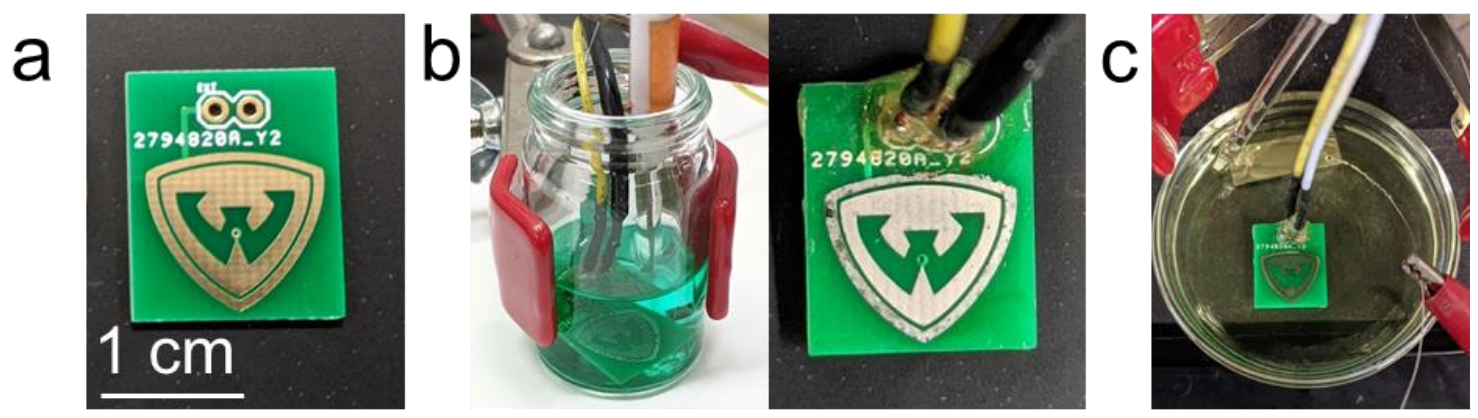

Figure S15. a, As-purchased PCB chip. b, The PCB chip during and after the Ni electrodeposition. $c$, The Ni-coated PCB chip inside the ME-gelation setup. The Wayne State University logo on the PCB chips was used with permission from Wayne State University. 


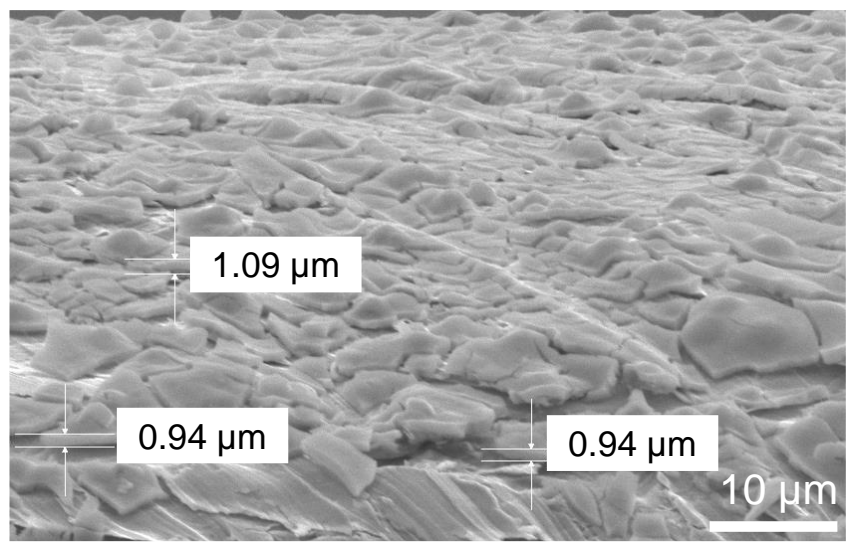

Figure S16. SEM image of a CdS ME-gel grown on a Ni foil electrode surface at $0.5 \mathrm{~V}$ for 1 hour,

a
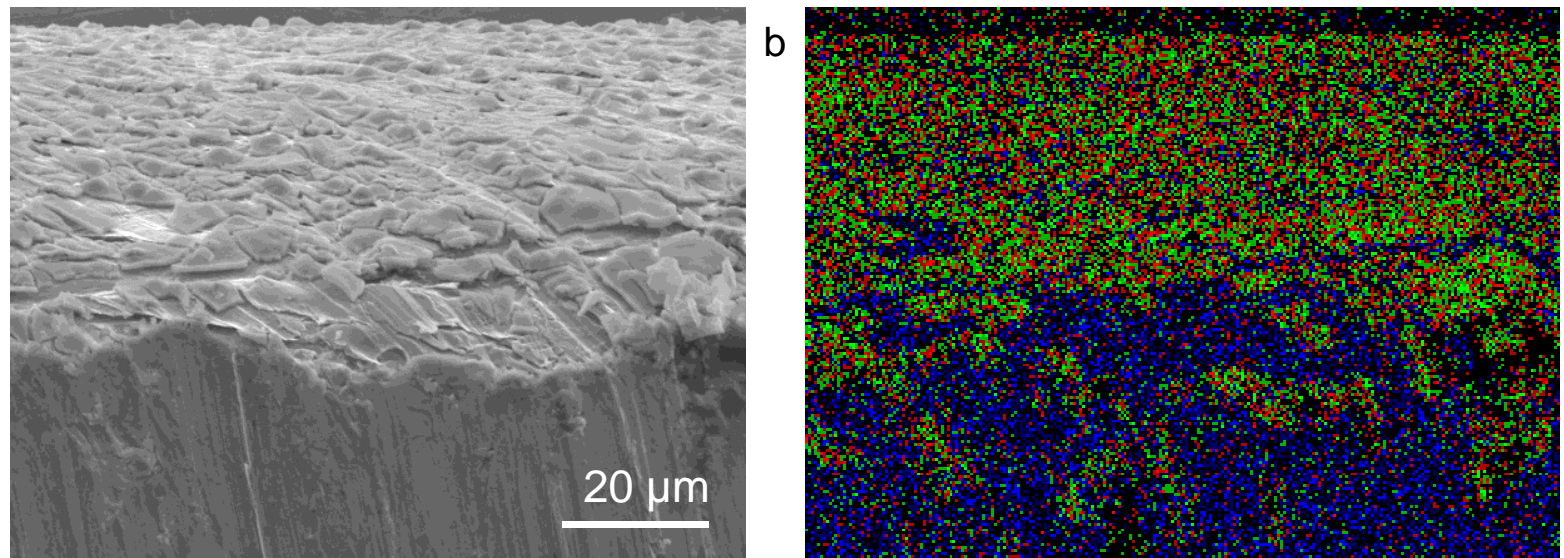

C
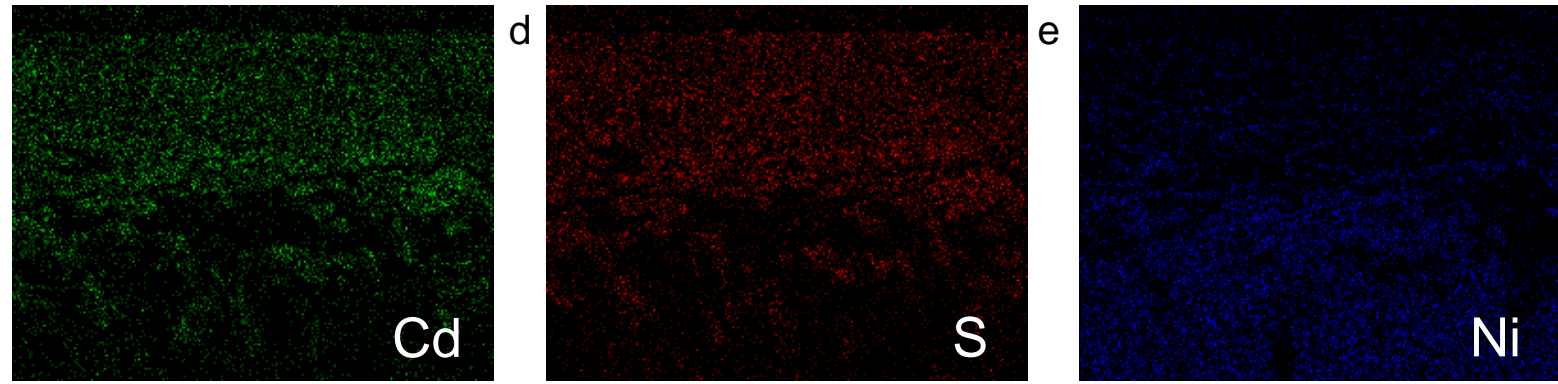

Figure S17. Elemental map of a CdS QD ME-gel grown on a Ni electrode. a, SEM image of the electrode area used for elemental mapping. b, Overlay of the elemental maps of Cd (green), S (red), and $\mathrm{Ni}$ (blue). c, d, and e, Elemental maps of $\mathrm{Cd}, \mathrm{S}$, and $\mathrm{Ni}$. 
Table S1. Comparison of surface area and pore size between the CdS QD ME-aerogel, MCaerogel, and the aerogels prepared by oxidative assembly methods.

\begin{tabular}{|c|c|c|c|}
\hline Sample & $\begin{array}{l}\text { BET surface } \\
\text { area }\left(\mathrm{m}^{2} / \mathrm{g}\right)\end{array}$ & $\begin{array}{l}\text { BJH average pore diameter } \\
(\mathrm{nm})\end{array}$ & $\begin{array}{l}\text { BJH cumulative pore } \\
\text { volume }\left(\mathrm{cm}^{3} / \mathrm{g}\right)^{(\mathrm{d})}\end{array}$ \\
\hline ME-aerogel (a) & 258 & $\begin{array}{l}24 \text { (adsorption isotherm) } \\
20 \text { (desorption isotherm) }\end{array}$ & 1.4 \\
\hline MC-aerogel (b) & 65 & $\begin{array}{l}14 \text { (adsorption isotherm } \\
11 \text { (desorption isotherm }\end{array}$ & 0.2 \\
\hline OE-aerogel (c) & 220 & $\begin{array}{l}23 \text { (adsorption isotherm) } \\
21 \text { (desorption isotherm) }\end{array}$ & 1.2 \\
\hline $\begin{array}{l}\text { Chemically } \\
\text { prepared oxidative } \\
\text { aerogel (c) }\end{array}$ & 155 & $\begin{array}{l}19 \text { (adsorption isotherm) } \\
17 \text { (desorption isotherm) }\end{array}$ & 0.7 \\
\hline
\end{tabular}

(a) prepared from TGA-capped CdS QD using a Ni electrode at $0.5 \mathrm{~V}$.

(b) prepared from a $\mathrm{Ni}^{2+} / \mathrm{MUA}$-capped CdS QD ratio of 2611.

(c) data obtained from reference ${ }^{1}$.

(d) Identical values were obtained from the adsorption and desorption isotherms.

Table S2. Comparison of the ME-gel growth after releasing similar amounts of $\mathrm{Ag}^{+}, \mathrm{Zn}^{2+}$ and $\mathrm{Co}^{2+}$ ions.

\begin{tabular}{|c|c|c|c|}
\hline Electrode material & $\mathrm{Ag}$ & $\mathrm{Zn}$ & Co \\
\hline $\begin{array}{l}\text { Amount of released } \\
\text { metal ions } \\
(\mathrm{mmol})\end{array}$ & 0.18 & 0.19 & 0.19 \\
\hline $\begin{array}{l}\text { Average gel } \\
\text { thickness } \\
(\mathrm{mm})\end{array}$ & 1.6 & 1.7 & 2.0 \\
\hline Before & & & \\
\hline After & & & \\
\hline
\end{tabular}




\section{References:}

1. Hewa-Rahinduwage, C. C.; Geng, X.; Silva, K. L.; Niu, X.; Zhang, L.; Brock, S. L.; Luo, L., Reversible Electrochemical Gelation of Metal Chalcogenide Quantum Dots. J. Am. Chem. Soc. 2020, 142 (28), 12207-12215. 